\title{
Is locking plate fixation a better option than casting for distal radius fracture in elderly people?
}

\author{
LP Hung *, YF Leung, WY Ip, YL Lee
}

\section{A B S T R A C T}

Objectives: To compare the outcomes of locking plate fixation versus casting for displaced distal radius fracture with unstable fracture pattern in active Chinese elderly people.

Design: Historical cohort study.

Setting: Orthopaedic ward and clinic at Tseung Kwan O Hospital, Hong Kong.

Patients: Between 1 May 2010 and 31 October 2013, 57 Chinese elderly people aged 61 to 80 years were treated either operatively with locking plate fixation $(n=26)$ or conservatively with cast immobilisation $(\mathrm{n}=31)$ for unstable displaced distal radius fracture.

Main outcome measures: Clinical, radiological, and functional outcomes were assessed at 9 to 12 months after treatment.

Results: The functional outcome (based on the quick Disabilities of the Arm, Shoulder and Hand score) was significantly better in the locking plate fixation group than in the cast immobilisation group, while clinical and radiological outcomes were comparable with those in other similar studies.

Conclusions: Locking plate fixation resulted in better functional outcome for displaced distal radius fracture with unstable fracture pattern in active Chinese elderly people aged 61 to 80 years. Further prospective study with long-term follow-up is recommended.

Hong Kong Med J 2015;21:407-10

DOI: 10.12809/hkmj144440

${ }^{1}$ LP Hung *, MRCSEd

${ }^{1}$ YF Leung, FHKAM (Orthopaedic Surgery)

${ }^{2}$ WY Ip, MS, FHKAM (Orthopaedic Surgery)

${ }^{1}$ YL Lee, FHKAM (Orthopaedic Surgery)

\section{Department of Orthopaedics and Traumatology, Tseung Kwan 0 \\ Hospital, Tseung Kwan O, Hong Kong \\ ${ }^{2}$ Department of Orthopaedics and Traumatology, Queen Mary Hospital, Pokfulam, Hong Kong}

* Corresponding author: joshua.hlp@gmail.com

New knowledge added by this study

- In active Chinese elderly people aged 61 to 80 years, apart from better clinical and radiological outcomes than cast immobilisation, locking plate fixation for displaced distal radius fracture with unstable fracture pattern also improves functional outcome.

Implications for clinical practice or policy

- We advise management of displaced distal radius fracture with unstable fracture pattern with locking plate fixation in active Chinese elderly people aged 61 to 80 years.

\section{Introduction}

Since the introduction of locking plate fixation there has been a tendency to manage distal radius fracture in elderly people with plate fixation over cast fixation. In the US, the rate of plate fixation in elderly people increased 5-fold from 3\% in 1996 to $16 \%$ by $2005 .^{1}$

Only a few recent studies have compared conservative versus operative management of distal radius fracture in elderly people. Some authors have concluded that, while grip strength was significantly better after operation, functional outcome did not improve., ${ }^{2,3}$

In Hong Kong, Chinese elderly people tend to have poorer bone quality than western people of the same age. ${ }^{4}$ Life expectancies in Hong Kong, however, are one of the longest in the world, at 80.9 years for men and 86.6 years for women in $2013 .{ }^{5}$ Moreover, an increasing number of people older than 60 years are still working and therefore the expectation for clinical outcomes after distal radius fracture will be higher than that in the past. As a result, it is imperative to investigate whether locking plate fixation is a good option in treating distal radius fracture in Chinese elderly people. The aim of this study was to compare the outcomes between locking plate fixation and cast immobilisation as treatment for displaced distal radius fracture with unstable fracture pattern in Chinese elderly people.

\section{Methods}

The hospital database was reviewed for elderly 


\section{老年橈骨遠端骨折的治療方式：鎖定鋼板固定術 是否比石亳固定好? \\ 洪亮斌、梁遠輝、葉永玉、李淵粦}

目的：活躍的華籍老年人在橈骨遠端骨折並出現移位及不穩定的情況 下, 比較鎖定鋼板固定術和石亳固定的治療結果。

設計：歷史隊列研究。

安排：香港將軍澳醫院的骨科病房及診所。

患者：2010年5月 1 日至2013年10月 31 日期間，共57名年齡介乎61至 80 歲有橈骨遠端骨折並出現移位及不穩定情況的華籍老年人, 其中 26 人接受鎖定鋼板固定手術, 另 31 人採取石膏固定作保守治療。

主要結果測量：治療後 9 至 12 個月進行臨床和影像學檢查, 以及功能 評估。

結果：根據上肢功能受損程度問卷（簡短版），接受鎖定鋼板固定術 的患者其關節功能評分較石膏固定的患者高, 其臨床及影像學結果則 與其他同類型研究相似。

結論：研究顯示, 對於年齡介乎 61 至 80 歲有橈骨遠端骨折並出現移位 及不穩定情況的活躍華籍老年人來説, 鎖定鋼板固定術有較佳功能結 果。建議進一步進行前瞻性長期隨訪研究。 patients with distal radius fracture from 1 May 2010 to 31 October 2013. The study was approved by the Research Ethics Committee of the Hospital Authority, Hong Kong.

The operation rate for distal radius fracture decreased with age and elderly patients ( $>70$ years) tended to prefer conservative management. The oldest patient who underwent locking plate fixation was 77 years. As a result, our inclusion criteria were: Chinese patients, aged 61 to 80 years, having displaced distal radius fracture with unstable fracture pattern (defined as having at least three out of five criteria of: initial dorsal angulation $>20^{\circ}$, initial shortening $>5 \mathrm{~mm},>50 \%$ dorsal comminution, intra-articular fracture, and ulnar fracture ${ }^{6}$ ), and completion of a rehabilitation programme after either operative or conservative management.

The exclusion criteria were: operative management other than 2.4- or 3.5-mm locking compression plates (eg K-wire fixation, non-locking plate fixation, or external fixation), open fracture or neurovascular deficits requiring immediate operative management, concomitant same-side upper limb injury (eg elbow dislocation, shoulder dislocation, or humeral fracture) that affected the overall functional outcome, and a history of medical illness (eg stroke or dementia) that hindered the rehabilitation results.

A total of 57 patients were identified. All of the patients were active, independent in activities of daily living, and otherwise healthy. The patients were admitted to orthopaedic ward at Tseung Kwan
O Hospital, Hong Kong from the Accident and Emergency Department. Initial closed reduction of distal radius fracture under local anaesthesia and immobilisation with a backslab were performed. Options of conservative management with cast immobilisation or operative management with locking plate fixation and the associated risks and complications were discussed with the patients. The patient made the final decision with written consent for either treatment.

For patients who opted for cast immobilisation, the reduced fracture was immobilised with a short arm cast for 6 weeks, followed by mobilisation and strengthening exercises. For patients who opted for locking plate fixation, the operation was done under general anaesthesia with an arm tourniquet. The modified Henry approach was used and the fracture was fixed with a 2.4- or 3.5-mm locking compression plate, followed by immediate mobilisation and then strengthening exercises. All patients were reviewed regularly in the orthopaedic out-patient clinic, with serial radiographs and rehabilitation until they reached the maximal improvement in range of motion and grip strength.

At the beginning of this retrospective study, the majority of the patients had been discharged from the clinic. In view of the technical difficulty of calling back elderly patients for physical assessment, the clinical parameters recorded in the last section of the rehabilitation programme were collected and the last radiographs taken in the clinic were retrieved for measurement. The duration from treatment to the last section of the rehabilitation programme averaged 10 months (range, 6-12 months) and the duration from treatment to the last radiographs averaged 9 months (range, 6-14 months).

Clinical parameters, including range of motion and grip strength of both hands, were measured by physiotherapists and occupational therapists not involved in this study. Radiographic parametersincluding volar tilt, radial inclination, radial length, and ulnar variance-were measured by one of the investigators.

Functional outcome was assessed using the quick Disabilities of the Arm, Shoulder and Hand questionnaire (DASH) score at a mean of 12 months (range, 6-24 months) after treatment; DASH score is a measure of a patient's perceived disability. The quick DASH was chosen instead of the full DASH because the elderly patients generally had a low educational background, making completion of a comprehensive questionnaire difficult. The 11-question evaluation was completed by means of an interview in the clinic, a telephone interview, or answers to a mailed questionnaire. In summary, clinical, radiological, and functional outcomes were assessed at 9 to 12 months after treatment.

Data were assessed with different statistical 
tests. For categorical variables, Chi squared test (for sex and side of injury) and analysis of variance (for Orthopaedic Trauma Association classification) were used. For continuous variables, independent sample $t$ test was used for normally distributed data (including grip strength and radiographic parameters) and Mann-Whitney $U$ test for nonnormally distributed data (including age, range of motion, and quick DASH score). A P value of $\leq 0.05$ was considered statistically significant.

\section{Results}

Of 57 patients enrolled in this study, 26 were treated with locking plate fixation and 31 were treated with cast immobilisation. The number of patients in the cast immobilisation group was low because many of them were either excluded due to stable fracture pattern $(n=31)$ or were lost to follow-up in the rehabilitation programme $(n=49)$. There were no statistically significant differences in characteristics between the two groups (Table 1).

Clinical outcomes are shown in Table 2. Grip strength was presented in the form of fraction of grip strength in the non-injured side as the denominator. The operative group did not achieve significantly better range of motion when compared with the cast immobilisation group, but grip strength was significantly better. Only one complication was documented, which was carpal tunnel syndrome after cast immobilisation. There was a statistically significant improvement in the radiographic parameters (except for radial length) after anatomical reduction in the operative group (Table 3). Regarding functional outcome, the operative group perceived significantly less disability than the cast immobilisation group (Table 4).

\section{Discussion}

This study found that locking plate fixation for displaced, unstable distal radius fracture achieved significantly better grip strength, radiographic parameters, and functional outcome when compared with cast immobilisation in elderly people aged 61 to 80 years.

Whether anatomical reduction results in better functional outcome in elderly people with displaced distal radius fracture of unstable fracture pattern is still a controversial topic. Some authors have reported satisfactory functional outcome after cast immobilisation for displaced distal radius fracture in low-demand elderly people, regardless of the radiographic result. ${ }^{7,8}$ In the younger age-group, reconstruction of articular congruity of displaced intra-articular distal radius fractures by means of internal fixation and/or external fixation have long been known to improve functional outcome. ${ }^{9}$ Only a few studies in the literature have investigated this
TABLE I. Patient characteristics

\begin{tabular}{lccc}
\hline Characteristic & $\begin{array}{c}\text { Locking plate } \\
\text { fixation }(\mathbf{n = 2 6})\end{array}$ & $\begin{array}{c}\text { Cast immobilisation } \\
(\mathbf{n = 3 1 )}\end{array}$ & P value \\
\hline Median age (years) & 65.0 & 64.0 & 0.255 \\
Sex & 5 & 7 & 0.757 \\
$\quad$ Male & 21 & 24 & \\
Female & & & 0.598 \\
Side of injury & 15 & 20 & \\
\hline Left & 11 & 11 & 0.892 \\
Right & & & \\
\hline OTA classification & 10 & 13 & \\
\hline A & 10 & 10 & \\
B & 6 & 8 & \\
\hline C & & & \\
\hline
\end{tabular}

Abbreviation: OTA = Orthopaedic Trauma Association

TABLE 2. Clinical outcomes

\begin{tabular}{lccc}
\hline Outcome & $\begin{array}{c}\text { Locking plate } \\
\text { fixation }(\mathbf{n}=\mathbf{2 6})\end{array}$ & $\begin{array}{c}\text { Cast immobilisation } \\
(\mathbf{n}=\mathbf{3 1})\end{array}$ & P value \\
\hline Median flexion $\left(^{\circ}\right)$ & 60.0 & 60.0 & 0.418 \\
\hline Median extension $\left(^{\circ}\right)$ & 60.0 & 60.0 & 0.749 \\
\hline Median supination $\left(^{\circ}\right)$ & 90.0 & 80.0 & 0.092 \\
Median pronation $\left(^{\circ}\right)$ & 85.0 & 90.0 & 0.707 \\
Grip strength ratio* $(\mathrm{kg} / \mathrm{kg})$ & $0.69 \pm 0.26$ & $0.52 \pm 0.28$ & 0.017 \\
\hline
\end{tabular}

* Means \pm standard deviations are shown

TABLE 3. Radiographic variables

\begin{tabular}{lccc}
\hline Variable & \multicolumn{2}{c}{ Mean \pm standard deviation } & P value \\
\cline { 2 - 3 } & $\begin{array}{c}\text { Locking plate } \\
\text { fixation }(\mathbf{n}=\mathbf{2 6})\end{array}$ & $\begin{array}{c}\text { Cast immobilisation } \\
(\mathbf{n}=\mathbf{3 1})\end{array}$ & \\
\hline Volar tilt $\left(^{\circ}\right)$ & $9.6 \pm 7.3$ & $-5.2 \pm 15.0$ & $<0.0001$ \\
\hline Radial inclination $\left(^{\circ}\right)$ & $21.0 \pm 4.6$ & $17.9 \pm 5.0$ & 0.019 \\
Radial length $(\mathrm{mm})$ & $9.8 \pm 2.4$ & $8.6 \pm 2.6$ & 0.072 \\
Ulnar variance $(\mathrm{mm})$ & $2.3 \pm 2.5$ & $4.0 \pm 2.2$ & 0.010 \\
\hline
\end{tabular}

TABLE 4. Functional outcome

\begin{tabular}{lccc}
\hline & $\begin{array}{c}\text { Locking plate } \\
\text { fixation }(\mathbf{n}=\mathbf{2 6})\end{array}$ & $\begin{array}{c}\text { Cast immobilisation } \\
(\mathbf{n}=\mathbf{3 1})\end{array}$ & P value \\
\hline Median DASH score $^{\star}$ & 4.5 & 13.6 & 0.040 \\
\hline
\end{tabular}

Abbreviation: DASH = Quick Disabilities of the Arm, Shoulder and Hand questionnaire

* DASH score: 0 = least disability; 100 = most disability

correlation in elderly patients.

One historical cohort study compared the outcomes of 90 patients older than 65 years who were treated either operatively with plate-and-screw fixation or external fixation, or conservatively with 
cast immobilisation. ${ }^{3}$ Grip strength and radiographic parameters were superior in the operative group, but there was no difference in other outcomes including DASH score. ${ }^{3}$ In one prospective randomised trial, 73 patients aged 65 years or older were randomised to receive open reduction internal fixation with volar locking plate or closed reduction and cast immobilisation. $^{2}$ Similar results were reported. Lastly, in one diagnostic study examining 53 patients older than 55 years, operative intervention was found to have no influence on functional outcome. ${ }^{10}$

Our study has a discrepancy for functional outcome, although clinical and radiological outcomes were consistent with the previous studies. Our opinion is that the previous studies included some patients older than 80 years, for whom operation might not be suitable due to poorer premorbid status and lower functional demand than those aged 61 to 80 years. Therefore, the overall functional outcome did not improve after operation. We believe that locking plate fixation for active Chinese elderly people aged up to 80 years could achieve good clinical, radiological, and functional outcomes. However, the decision should not only be determined by chronological age but also be balanced with functional age and medical condition.

There are some limitations to this study. Since it is a non-randomised study, there might have been bias during discussion of the treatment options with the patients. Moreover, the two groups of patients were not blinded (and could not be blinded) to the therapists and investigator in assessing the clinical and radiological outcomes, which might have resulted in information bias. A substantial number of eligible patients defaulted the rehabilitation programme (four in the operative group, 49 in the cast immobilisation group) and were counted as loss to follow-up. Therefore, there was a possibility of self-selection bias among the remaining patients, who had better motivation for rehabilitation and regaining functions. Other confounding factors, such as differences in background characteristics and expectations of outcome, might have made the two groups of patients non-comparable. The followup duration was relatively short due to limitations of human resources. The times for assessing outcomes were not standardised due to the retrospective nature of this study. The sample size was relatively small due to the strict inclusion and exclusion criteria, especially after exclusion of patients older than 80 years, but this resulted in significantly better functional outcome. Lastly, the quick DASH score might have been affected by previous injury or degenerative arthritis of the same upper limb. Using a wrist-specific score such as the Mayo wrist score or Patient-Rated Wrist Evaluation, however, could not reflect how the whole upper limb compensates for the wrist function in elderly patients after distal radius fracture.

\section{Conclusions}

We advise operation with locking plate fixation for displaced distal radius fracture with unstable fracture pattern in active Chinese elderly patients aged 61 to 80 years. Nevertheless, further prospective study such as a randomised controlled trial is needed to resolve this controversy.

\section{Acknowledgements}

Special thanks to the many dedicated colleagues from the Physiotherapy and Occupational Therapy Departments of Tseung Kwan O Hospital.

\section{References}

1. Chung KC, Shauver MJ, Birkmeyer JD. Trends in the United States in the treatment of distal radial fractures in the elderly. J Bone Joint Surg Am 2009;91:1868-73.

2. Arora R, Lutz M, Deml C, Krappinger D, Haug L, Gabl M. A prospective randomized trial comparing nonoperative treatment with volar locking plate fixation for displaced and unstable distal radial fractures in patients sixty-five years of age and older. J Bone Joint Surg Am 2011;93:2146-53.

3. Egol KA, Walsh M, Romo-Cardoso S, Dorsky S, Paksima N. Distal radial fractures in the elderly: operative compared with nonoperative treatment. J Bone Joint Surg Am 2010;92:1851-7.

4. Lau EM, Lynn H, Woo J, Melton LJ 3rd. Areal and volumetric bone density in Hong Kong Chinese: a comparison with Caucasians living in the United States. Osteoporos Int 2003;14:583-8.

5. Stoker S, editor. Hong Kong 2013. Information Services Department, Hong Kong Special Administrative Region Government; 2013.

6. Lafontaine M, Hardy D, Delince P. Stability assessment of distal radius fractures. Injury 1989;20:208-10.

7. Anzarut A, Johnson JA, Rowe BH, Lambert RG, Blitz S, Majumdar SR. Radiologic and patient-reported functional outcomes in an elderly cohort with conservatively treated distal radius fractures. J Hand Surg Am 2004;29:1121-7.

8. Young BT, Rayan GM. Outcome following nonoperative treatment of displaced distal radius fractures in lowdemand patients older than 60 years. J Hand Surg Am 2000;25:19-28.

9. Trumble TE, Schmitt SR, Vedder NB. Factors affecting functional outcome of displaced intra-articular distal radius fractures. J Hand Surg Am 1994;19:325-40.

10. Synn AJ, Makhni EC, Makhni MC, Rozental TD, Day CS. Distal radius fractures in older patients: is anatomic reduction necessary? Clin Orthop Relat Res 2009;467:161220 . 